\title{
Dopamine D3-Like Receptors Modulate Anxiety-Like Behavior and Regulate GABAergic Transmission in the Rat Lateral/Basolateral Amygdala
}

\author{
Marvin R Diaz', Ann M Chappell', Daniel T Christian', Nancy J Anderson' and Brian A McCool*,' \\ 'Department of Physiology and Pharmacology, Wake Forest University School of Medicine, Winston-Salem, NC, USA
}

\begin{abstract}
Central among the brain regions that regulate fearlanxiety behaviors is the lateral/basolateral amygdala (BLA). BLA output is tightly controlled by the relative activity of two populations of inhibitory GABAergic interneurons, local feedback cells distributed throughout the nucleus, and feedforward cells found along the lateral paracapsular border of this subdivision. Recent studies suggest that dopamine (DA) can modulate the BLA GABAergic system, thus linking fear/anxiety states with mesolimbic reward/attentional processes. However, the precise dopaminergic mechanisms regulating the activity of the two BLA GABAergic neuron populations have not been fully explored. We therefore examined the effects of DA D3-like receptors on BLA-dependent anxiety-like behavior and neurophysiology. After confirming the presence of D3-like receptors within the BLA, we found that microinjection of a D3-selective antagonist into the BLA decreased anxiety-like behavior expressed in both the light/dark transition test and the elevated plus maze. Consistent with this, we found that in vitro D3-like receptor activation selectively inhibits synaptic transmission at both BLA feedback and feedforward GABAergic interneuron populations, with no effect on glutamatergic transmission. This inhibition of GABAergic transmission is a result of a D3-like receptor-mediated, dynamin-dependent process that presumably reflects endocytosis of postsynaptic $G_{A B} A_{A}$ receptors found on principal BLA neurons. Because environmental cues alter both DA release and relative activity states of the BLA, our data strongly suggest that DA, potentially acting through D3-like receptors, may suppress the relative contribution by inhibitory processes in the BLA and modify the expression of BLA-related behaviors.

Neuropsychopharmacology (20II) 36, 1090-I 103; doi:10.1038/npp.2010.246; published online 26 January 20II
\end{abstract}

Keywords: anxiety; dopamine; electrophysiology; GABAergic synapse; U99194; endocytosis

\section{INTRODUCTION}

There is an extensive literature highlighting a close relationship between anxiety-like behavior and the mesolimbic dopamine (DA) system. Dopaminergic mechanisms alter behavioral responses to naturally anxiogenic environmental stimuli (Kienast et al, 2008; Talalaenko et al, 1994). In addition, the DA system and anxiety-like behavior are both dramatically altered by early-life stressors (Higley et al, 1991; Matthews et al, 2001) and withdrawal from chronic drug exposure (Finckh et al, 1997; Nath et al, 2000; Yang et al, 1992). Manipulation of the DA system in the amygdala, a central component of the neural circuitry controlling anxiety-related behavior, recapitulates many of

*Correspondence: Dr BA McCool, Department of Physiology and Pharmacology, Wake Forest University School of Medicine, Medical Center Boulevard, Winston-Salem, NC 27I57, USA, Tel: + I 336716 8534, Fax: + | 336 7I6 850 I, E-mail: bmmcool@wfubmc.edu Received 30 September 2010; revised 14 December 2010; accepted 17 December 2010 these findings (de la Mora et al, 2005; Weiss et al, 2001), suggesting that the amygdala DA system is critical for the expression of anxiety. The neurobiological mechanisms governing these relationships have not been firmly established.

The rat amygdala, a central regulatory component of the limbic system, contains five major nuclei that coordinate a multitude of brain regions responsible for different aspects of affective behaviors like fear/anxiety. The lateral and basolateral subdivisions (basolateral amygdala (BLA)) are the primary 'input' nuclei (Pitkanen et al, 1997) and are composed of large, pyramidal-shaped glutamatergic projection neurons. In addition to their excitatory inputs from diverse cortical and thalamic regions, at least two populations of GABAergic interneurons, the lateral paracapsular cells (LPCs) and scattered 'local' cells, tightly regulate the activity of BLA principal neurons. LPC GABAergic neurons are concentrated in 'islands' found along the lateral border of the BLA and provide feedforward inhibition in response to excitatory cortical inputs (Marowsky et al, 2005). 'Local' interneurons provide synchronous feedback inhibition in 
response to glutamatergic collaterals arising from the principal BLA neurons themselves (Woodruff et al, 2006). This complex BLA GABAergic circuitry controls the acquisition and expression of different measures of conditioned fear (Davis, 2000), the expression of anxiety-like behavior in response to naturally aversive stimuli (Sanders and Shekhar, 1995), and following drug withdrawal (Isoardi et al, 2007). The parallels between the role of these BLA GABAergic interneuron populations and the dopaminergic system suggest a potential interaction between these neurotransmitters. Recent evidence supports this hypothesis and suggests that DA directly acts upon BLA GABAergic neurotransmission. Activation of D2-like receptors (D2Rs) disinhibits the lateral amygdala (LA) in mice (Bissiere et al, 2003) by suppressing GABAergic neurotransmission. These effects may be complex and dependent on the specific GABAergic interneuron population. For example, BLA D1Rs suppress LPC-mediated GABAergic feedforward inhibition (Marowsky et al, 2005) and simultaneously enhance local BLA interneuron excitability (Kroner et al, 2005).

In addition to the expression of D1R and D2R in the BLA, there is some evidence suggesting that DA D3Rs also play a functional role in this brain region. There is marked expression of D3R binding sites within BLA (CamachoOchoa et al, 1995), and microinjection of the D3R antagonist nafadotride into the BLA suppresses amphetamine-enhanced appetitive conditioning (Phillips et al, 2002). These data suggest a functional role for D3Rs in the BLA. Unlike DA D1R and D2R, the physiological role of BLA D3 receptors has not been explored. In this study, we examine the neurobiological mechanisms that underlie the behavioral effects of BLA D3Rs using both behavioral pharmacology and in vitro physiology.

\section{MATERIALS AND METHODS}

\section{Animals}

All experiments used male Sprague-Dawley rats (Harlan, Indianapolis, IN). The WFUSM Animal Care and Use Committee Experimental approved all animal procedures in accordance with the NIH Guidelines for the Care and Use of Laboratory Animals.

\section{Surgical Procedure and Microinjections}

Using previously published procedures (Lack et al, 2007), we anesthetized adult rats (300 g, $n=24$ ) with pentobarbital and implanted with guide cannulae directed at the dorsal aspect of the LA according to the following stereotaxic coordinates (millimeters relative to Bregma; Paxinos and Watson, 1997): -2.80 anterior/posterior, +5.05 lateral on the right, +5.25 lateral on the left, and $-6.20 \mathrm{dorsal} / \mathrm{ventral}$ from the top of the brain. During a 5-day recovery period, animals were extensively handled and repeatedly exposed to the manipulations associated with the microinjection procedure. On injection days, injection cannulae were placed such that their tips extended $1 \mathrm{~mm}$ below the ventral aspect of the guide cannulae, and animals received $0.5 \mu \mathrm{l}$ of either of the D3 receptor antagonists, U99194 or GR103691, delivered over a $30 \mathrm{~s}$ period. Injection cannulae were left in place for an additional $1 \mathrm{~min}$ before being removed. Animals receiving the sham injection were subjected to the same procedure, but were injected with artificial cerebrospinal fluid (aCSF, see below). Animals received three microinjections, once a week, for three consecutive weeks, and were exposed to a different behavioral apparatus each (see below). Animals were counter-balanced across injection days such that they never received the same dose of U99194 or GR103691 (or sham) across the three injection weeks. Placement of the guide cannulae was confirmed post mortem by preparing coronal slices from fixed tissue. Tip placements are shown in Figure 1a. Tip locations from adjacent anteroposterior slices were combined for simplicity. Four out of 24 surgeries resulted in cannulae placements outside the target area for the U99194 experiments and seven out of 22 surgeries in the GR103691 experiments; these 'miss' animals are not included in the analysis.

\section{Behavioral Assays}

To assess the effects of U99194 and GR103691 microinjected into the BLA, we employed two different anxiety assays and a separate apparatus to assess locomotion. For the light/ dark box (Isoardi et al, 2007; McCool et al, 2003), individuals were placed in the 'light' side of a $40 \mathrm{~cm} \times 40 \mathrm{~cm}$ plexiglass arena divided equally into 'light' and 'dark' sides by an opaque plexiglass insert (Rat TruScan Activity Arena, Coulbourn Instruments, Allentown, PA). The 'light side' of the arena was illuminated by ambient room lighting to $\sim 400 \mathrm{~lx}$. Two infrared sensor rings surrounded the entire apparatus, one in the floor plane and one located $\sim 15 \mathrm{~cm}$ above the floor to measure rearing behavior. Data were collected for $5 \mathrm{~min}$ at $0.25 \mathrm{~Hz}$ and analyzed for the total number of moves, the time to leave the light side following initial placement (egress latency), the time to return to the light side after initial entry to the dark side (re-entry latency), the total time spent in the light and dark compartments, the number of light-dark transitions, and the number of vertical beam breaks. Between animals, the apparatus was cleaned with warm water, $70 \%$ ethanol, again with warm water, and thoroughly dried.

In the second microinjection week, sessions were performed using the elevated plus maze (Pellow et al, $1985)$ with incandescent lighting ( $\sim 40 \mathrm{~lx}$ on the open arms). The apparatus consists of open and closed runways $(20$ in $\times 4$ in) that set atop a 28.5 in $(72.4 \mathrm{~cm})$ high aluminum frame (Med Associates, St Albans, VT). Animal entry into open and closed arms were detected with infrared sensors attached at the opening to each arm; data acquisition was achieved with a personal computer interfaced with control units and programmed using MED-PC (Med Associates). Dependent variables included the total amount of time an animal spent in each arm, the total amount of time the animal spent at the central junction, and the number of transitions between arms. At the beginning of each 5-min session, individuals were placed at the junction of the open and closed arms facing an open arm. Between animals, the apparatus was cleaned with warm water, $70 \%$ ethanol, again with warm water, and thoroughly dried.

Locomotor activity was measured in an open field on the third week (Steiner et al, 1997). Animals were placed in the 

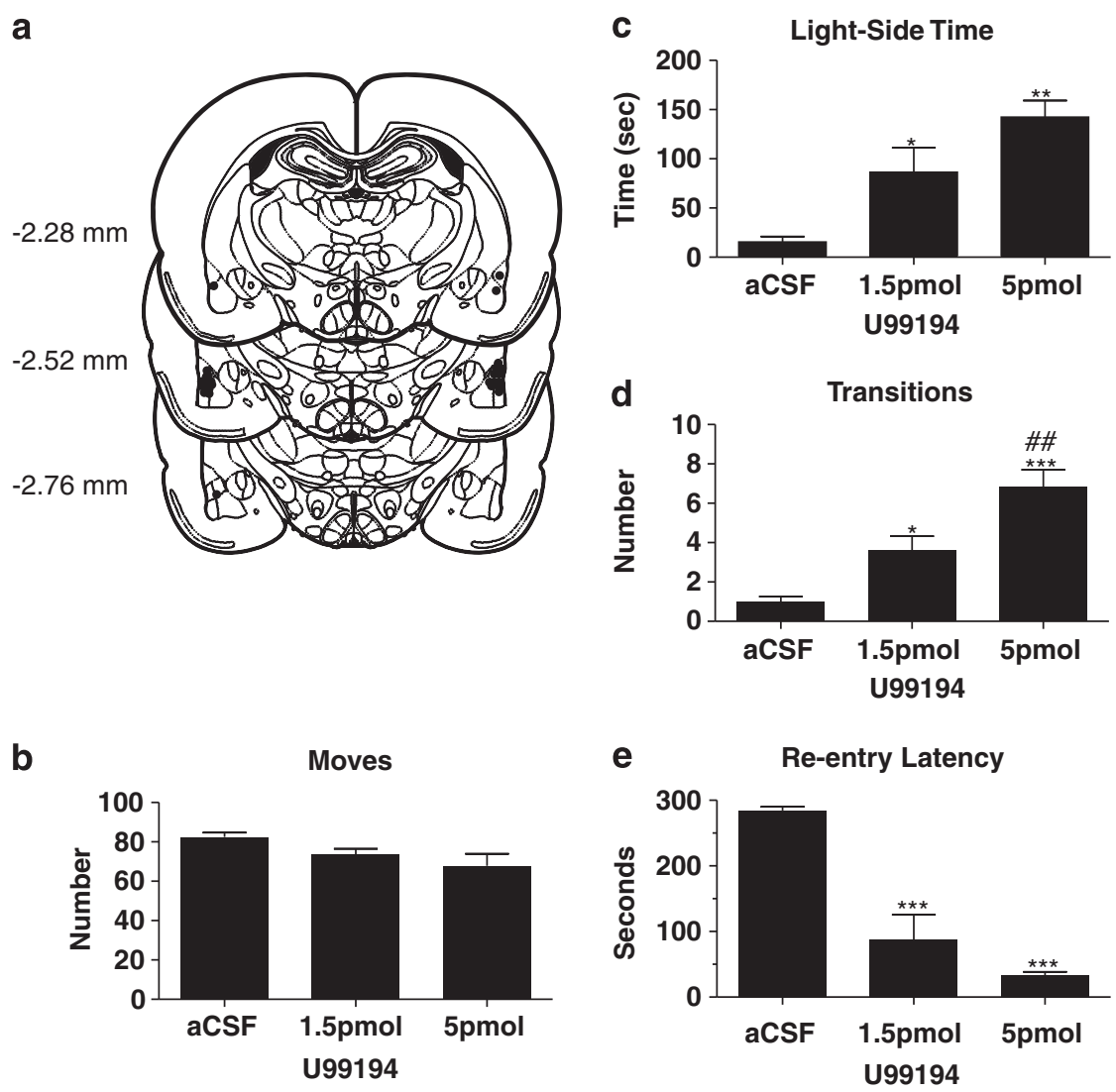

Figure I U99194 effects on anxiety-like behavior expressed in a light/dark box. The approximate location of guide cannulae tips are indicated by the closed circles (a). Anterior-to-posterior stereotaxic coordinates of representative coronal brain slices are shown at left (Paxinos and Watson, 1997). (b) U99194 did not significantly affect the number of movements in the light/dark arena ( $n=6$ animals for artificial cerebrospinal fluid (aCSF) group, $n=8$ for 1.5 pmol group, and $n=6$ for 5 pmol group, $P>0.05$, one-way analysis of variance (ANOVA)). Intra-basolateral amygdala (BLA) U99|94 increased time spent in light side compared with vehicle-injected (c) and increased number of transitions from dark to light side (d). U99 I 94 also decreased re-entry latency to the dark side compared with vehicle injected (e). Newman-Keuls post-test compared the individual columns: $* P<0.05$, $* * P<0.0$ I, and $* * * P<0.00$ I compared with sham; ${ }^{\#} P<0.01$ compared with the 1.5 pmol dose.

center of a $40 \mathrm{~cm} \times 40 \mathrm{~cm}$ plexiglass arena (Rat TruScan Activity Arena), and the number of movements, movement distance, and move time was recorded in the dark for $5 \mathrm{~min}$ using infrared sensor rings.

\section{Slice Preparation}

For the in vitro electrophysiology experiments, coronal amygdala slices were prepared from male Sprague-Dawley rats (100-150 g, 3-5 weeks of age) as described previously (Isoardi et al, 2007; McCool et al, 2003). Slices were submerged in room temperature $\left(\sim 25^{\circ} \mathrm{C}\right)$, oxygenated aCSF containing (in $\mathrm{mM}$ ): $126 \mathrm{NaCl}, 3 \mathrm{KCl}, 1.25 \mathrm{NaH}_{2} \mathrm{PO}_{4}$, $2 \mathrm{MgSO}_{4}, 26 \mathrm{NaHCO}_{3}, 10$ glucose, and $2 \mathrm{CaCl}_{2} \cdot 2 \mathrm{H}_{2} \mathrm{O}$. Slices were maintained in aCSF for $\sim 1 \mathrm{~h}$ before recording. All experiments were performed $1-4 \mathrm{~h}$ after preparation of the BLA slices.

\section{Whole-Cell Patch-Clamp Recording}

Methods for whole-cell voltage clamp recording BLA GABAergic neurotransmission were similar to those reported previously (DuBois et al, 2006; Isoardi et al, 2007). Briefly, slices were placed in a recording chamber that was continuously perfused with room-temperature aCSF at a rate of $2 \mathrm{ml} / \mathrm{min}$. Input resistance was $8-12 \mathrm{M} \Omega$ when electrodes were filled with an internal solution containing (in $\mathrm{mM}$ ): $122 \mathrm{Cs}$-gluconate, $10 \mathrm{CsCl}, 10$ HEPES, 1 EGTA, $5 \mathrm{NaCl}, 0.1 \mathrm{CaCl}_{2}, 4 \mathrm{Mg}$-ATP, $0.3 \mathrm{Na}-\mathrm{GTP}$, and 2 QX314-(Cl), pH 7.25 and osmolarity $280-290 \mathrm{mOsm}$. Data were acquired with an Axopatch 200B amplifier (Axon Instruments, Foster City, CA) and stored for later analysis using ClampEx software (Axon Instruments, Foster City, CA). GABA $\mathrm{A}^{-}$ mediated synaptic currents were pharmacologically isolated using 6,7-dinitroquinoxaline-2,3(1H,4H)-dione (DNQX, $20 \mu \mathrm{M}$, an AMPA/kainate receptor antagonist; SigmaAldrich, St Louis, MO), DL-2-amino-5-phosphono-pentanoic acid (APV, $50 \mu \mathrm{M}$, an NMDA receptor antagonist; SigmaAldrich), and the $\mathrm{GABA}_{\mathrm{B}}$ antagonists SCH50911 $(10 \mu \mathrm{M})$ or CGP55845 $(10 \mu \mathrm{M})$. Glutamatergic synaptic currents were pharmacologically isolated using the $\mathrm{GABA}_{\mathrm{A}}$ antagonist bicuculline methochloride $(10 \mu \mathrm{M})$ and SCH50911. Only neurons with a high membrane capacitance $(>100 \mathrm{pF})$ and low input resistance $(<30 \mathrm{M} \Omega)$ were considered presumptive principal neurons (Faber et al, 2001; Kroner et al, 2005; Schiess et al, 1993; Washburn and Moises, 1992) and were included in this study.

Electrically evoked GABA synaptic response was stimulated using a range of intensities to achieve an average synaptic response of $\sim 100 \mathrm{pA}$ with a holding potential at 
$-10 \mathrm{mV}$. The stimulating electrodes were placed in the external capsule (to activate LPCs) and medial to the recording electrode (to activate local interneurons) as specified within each experiment. For experiments measuring glutamatergic neurotransmission, the holding potential was $-60 \mathrm{mV}$ and a stimulating electrode was placed in the LA to electrically activate glutamatergic projections as reported previously (Isoardi et al, 2007). Slices were perfused with a D3R agonist PD128907 and/or the D3-selective receptor antagonists such as U99194 maleate, GR103691, or a D2-selective receptor antagonist such as L741626 (Tocris Bioscience, Ellisville, MO). To block dynamin-dependent endocytosis of $\mathrm{GABA}_{\mathrm{A}}$ receptors, dynamin inhibitory peptide ( $\mathrm{p} 4)$ or scrambled control peptide (Tocris) was included in the intracellular pipette solution.

\section{Paired-Pulse Ratio}

Paired-pulse ratio (PPR) was measured with two equalintensity electrical stimulations with a 50 - or 250 -ms interpulse interval. A ratio of the amplitudes of the evoked inhibitory postsynaptic currents (IPSCs) was taken (second amplitude divided by the first). Measurements were taken before (baseline) and during maximal drug effect from both GABAergic interneuron populations. All values are expressed as mean \pm SEM. PPR data were subjected to a paired $t$-test with $P<0.05$ considered statistically significant.

\section{Spontaneous GABAergic Synaptic Events}

Miniature IPSCs (mIPSCs) were acquired at $20 \mathrm{kHz}$, and were filtered at $2 \mathrm{kHz}$. For this set of experiments, an internal solution consisting of (in $\mathrm{mM}$ ): $135 \mathrm{KCl}, 10$ HEPES, $2 \mathrm{MgCl}_{2}, 0.5$ EGTA, $5 \mathrm{Mg}$-ATP, $1 \mathrm{Na}-\mathrm{GTP}$, and 1 QX314-(Cl), pH 7.25 and osmolarity $280-290 \mathrm{mOsm}$. Following isolation of GABAergic transmission using DNQX and APV (as used with electrically evoked experiments) and complete attenuation of evoked responses with $1 \mu \mathrm{M}$ tetrodotoxin (TTX) (94.38 $\pm 3.53 \%$ inhibition), mIPSCs were recorded for $1 \mathrm{~min}$ (baseline) and for $1 \mathrm{~min}$ after a $10 \mathrm{~min}$ PD128907 application. Access resistance was measured throughout recordings and cells with changes in access resistance $>20 \%$ were not included in the analysis. These experiments were performed at a holding potential of $-60 \mathrm{mV}$. Event amplitude and frequency were analyzed using MiniAnalysis (SynaptSoft Inc). Median values from individual cells were averaged across treatment groups (Isoardi et al, 2007) and reported as mean \pm SEM.

\section{Western Blots}

Lysis buffer $(7 \mu \mathrm{l} / \mathrm{mg}$ tissue; $10 \mathrm{mM}$ Tris, $\mathrm{pH}$ 7.4, $2 \%$ sodium dodecyl sulfate, $1 \mathrm{mM}$ EDTA, $\mathrm{pH} 8$, and protease inhibitors for mammalian tissue (Sigma, St Louis, MO)) was added to the nucleus accumbens (NAcc) and BLA was dissected from coronal slices, and the tissue was disrupted by brief sonication and incubated at $4{ }^{\circ} \mathrm{C}$ on a rotisserie mixer for $2 \mathrm{~h}$. Protein yield was quantified using the BCA assay (Thermal Scientific, Rockford, IL). Twenty micrograms of total protein was loaded onto 8-16\% sodium dodecyl sulfate precast polyacrylamide gels (Thermal Scientific), separated by electrophoresis, and transferred to a nitrocellulose membrane (Hybond N; Amersham, Piscataway, NJ). The membrane was blocked with 5\% non-fat dry milk (NFM) in Tris-buffered saline (TBS-T; $150 \mathrm{mM} \mathrm{NaCl}$, $5.2 \mathrm{mM} \mathrm{Na}_{2} \mathrm{HPO}_{4}, 1.7 \mathrm{mM} \mathrm{KH}_{2} \mathrm{PO}_{4}, 0.05 \%$ Tween-20). Blots were incubated overnight at $4{ }^{\circ} \mathrm{C}$ in $\mathrm{TBS}-\mathrm{T} / 1 \% \mathrm{NFM}$ containing $8.5 \mu \mathrm{g} / \mathrm{ml}$ rabbit anti-rat D3 DA receptor affinity-purified polyclonal antibody (no. AB1786P; Millipore, Temecula, CA). Following extensive washing with TBS-T, the blots were exposed to a goat anti-rabbit, HRPlabeled secondary antibody (1:3000 dilution; Sigma) for $1.5 \mathrm{~h}$ at room temperature with agitation. Detection of bound secondary antibody was performed using SuperSignal West Dura Extended Duration Substrate (Thermal Scientific). Band intensity was quantified from digital images captured on a CCD camera using a Bio Rad ChemiDoc XRS Imaging System with Quantity One Analysis Software (Hercules, CA).

\section{Statistics}

Behavioral data were analyzed using a standard one-way ANOVA. Electrically evoked and miniature IPSC data were analyzed with either un-paired or paired $t$-tests whenever appropriate. $P<0.05$ was considered statistically significant.

\section{RESULTS}

\section{BLA D3Rs Modulate Anxiety-Like Behaviors}

Recent reports of D3R modulation of BLA-dependent conditioned behaviors (Phillips et al, 2002) and the reduced anxiety-like behavior in D3R knockout mice (Steiner et al, 1997) suggested to us that these receptors might modulate native responses to emotionally relevant stimuli. To test this hypothesis, we examined the effects of two D3R-selective antagonists, U99194 (14-fold affinity for D3:D2) and GR103691 (60-fold affinity for D3:D2) (Audinot et al, 1998). We microinjected 1.5 and 5 pmol of the U99194 or aCSF bilaterally into the BLA of 24 animals. In a separate set of animals $(n=22)$, we microinjected 0.5 pmol of the GR103691 or aCSF bilaterally into the BLA. Post hoc anatomical analysis revealed that guide cannulae were implanted outside the target area in four out of 23 surgeries in the U99194 experiments (Figure 1a) and in seven out of 22 surgeries in the GR103691 experiments (not shown). These 'miss' animals are included as 'site controls' in a separate data analysis.

When tested in the light/dark box (Figure 1a), intra-BLA U99194 significantly increased both the total time spent on the light side (Figure 1c: aCSF-15.4 $\pm 5.6 \mathrm{~s}, n=6$; $1.5 \mathrm{pmol}$ U99194-86.4 $\pm 24.8 \mathrm{~s}, \quad n=8 ; \quad 5 \mathrm{pmol} \quad$ U99194-142.3 \pm $16.8 \mathrm{~s}, \quad n=6$; out of $300 \mathrm{~s}$ total; one-way ANOVA $(P<0.01) ; \mathrm{F}=9.4$ (Newman-Keuls $P<0.05))$ and the total number of transitions between the light and dark sides of the apparatus (Figure 1d: aCSF $-1.0 \pm 0.3 ; 1.5 \mathrm{pmol}$ U99194-3.6 $\pm 0.8 ; \quad 5$ pmol U99194-6.8 $\pm 0.9 ; \quad$ one-way ANOVA $(P<0.0001) ; \mathrm{F}=16.5$ (Newman-Keuls, aCSF $v s$ 1.5 and 5 pmol $P<0.001,1.5$ vs 5 pmol $P<0.01)$ ). U99194 modestly increased the egress latency at both the $1.5 \mathrm{pmol}$ $(33.8 \pm 10.5 \mathrm{~s})$ and $5 \mathrm{pmol}$ doses $(36.2 \pm 5.0 \mathrm{~s})$ relative to sham $(15.7 \pm 5.8 \mathrm{~s})$, but this did not reach statistical 
significance. U99194 had no significant effects on either the total number of moves in the apparatus (Figure 1b) or the number of vertical rears (not shown).

Similar to U99194, intra-BLA microinjection of GR103691 significantly increased the total time spent on the light side of the light/dark box (aCSF-13.7 $\pm 3.2 \mathrm{~s}, n=7 ; 0.5 \mathrm{pmol}$ GR103691 $-69.5 \pm 17.93 \mathrm{~s}, \quad n=7$; out of $300 \mathrm{~s}$ total; $\mathrm{F}=30.65, P<0.01, t$-test). GR103691 slightly increased the total number of transitions between the light and dark sides $(\mathrm{aCSF}-2.4 \pm 0.08 ; 0.5 \mathrm{pmol}-4.3 \pm 1.3 ; \mathrm{F}=2.26, P>0.05$, $t$-test) without reaching statistical significance, but did significantly increase the egress latency $(\mathrm{aCSF}-13.3 \pm 3.3 \mathrm{~s}$; $0.5 \mathrm{pmol}-32.00 \pm 4.1 \mathrm{~s} ; \mathrm{F}=1.57, P<0.01, t$-test $)$. Similar to U99194, GR103691 did not significantly alter the total number of moves or the number of vertical rears (not shown).

The light/dark box data suggested that intra-BLA microinjections of a D3R antagonist reduced anxiety-like behaviors. To confirm this, we also measured the effects of bilateral U99194 and GR103691 BLA microinjection in the elevated plus maze. Intra-BLA U99194 (Table 1) significantly increased the time spent on the open arms $(\mathrm{F}=15.7, P<0.001)$ and significantly decreased time on the closed arms $(\mathrm{F}=9.7, P<0.01)$ without altering the time spent in the junction between the open and closed arms $(\mathrm{F}=0.04 ; P>0.05)$ during the 300 second assay. Likewise, intra-BLA U99194 significantly increased the number of open-arm entries whether these data were expressed as the total number of open-arm entries $(\mathrm{F}=20.4, P<0.001)$ or as the percentage of open-arm entries (open-arm entries/total arm entries; $\mathrm{F}=10.8, P<0.001)$. Newman-Keuls post-tests suggested that all these effects were all dose-dependent (see Table 1). Intra-BLA U99194 did not significantly alter the number of closed-arm entries $(\mathrm{F}=0.08, P>0.05)$. Intra-BLA GR103691 likewise significantly increased the time on the open arms $(\mathrm{aCSF}=1.37 \pm 1.37 \mathrm{~s} ; 0.5 \mathrm{pmol}=19.44 \pm 3.58 \mathrm{~s}$; $\mathrm{F}=9.5, P<0.01, t$-test) without changing the time on the closed arms $(\mathrm{aCSF}=247.8 \pm 15.91 \mathrm{~s} ; \quad 0.5 \mathrm{pmol}=222.1 \pm$ $15.80 \mathrm{~s} ; \mathrm{F}=1.3, P>0.05, t$-test), junction time (aCSF $=$ $51.02 \pm 15.07 \mathrm{~s} ; 0.5 \mathrm{pmol}=47.31 \pm 10.15 \mathrm{~s} ; \mathrm{F}=1.8, P>0.05$, $t$-test), the total number of open-arm entries $(\mathrm{aCSF}=0.67 \pm$ $0.67 ; 0.5 \mathrm{pmol}=1.75 \pm 0.41 ; \mathrm{F}=1.9, P>0.05, t$-test), or the total number of closed-arm entries $(\mathrm{aCSF}=9.16 \pm 2.79$; $0.5 \mathrm{pmol}=8.0 \pm 1.76 ; \mathrm{F}=1.9, P>0.05, t$-test $)$.

Data from both the light/dark box and the plus maze suggest that intra-BLA U99194 did not substantially alter locomotor behaviors. To examine this directly, we tested the effects of U99194 microinjection on open-field behavior (Table 2). Intra-BLA U99194 did not alter the total number of moves ( $\mathrm{F}=0.06, P>0.05$, one-way ANOVA), the total movement distance $(\mathrm{F}=1.00, P>0.05)$, the amount of time spent moving $(\mathrm{F}=0.33, P>0.05)$, or the number of vertical rears $(F=0.9, P>0.05)$. Likewise, GR103691 had no effect on the number of moves $(\mathrm{aCSF}=78.17 \pm 3.41 ; 0.5 \mathrm{pmol}=$ $73.16 \pm 3.55 ; \mathrm{F}=1.08, P>0.05, t$-test $)$, the total movement distance $(\mathrm{aCSF}=1613.95 \pm 59.81 \mathrm{~cm} ; 0.5 \mathrm{pmol}=1820.46 \pm$ $102.69 \mathrm{~cm} ; \mathrm{F}=2.94, P>0.05)$, the amount of time spent moving $(\mathrm{aCSF}=230.91 \pm 4.12 \mathrm{~s} ; 0.5 \mathrm{pmol}=238.58 \pm 5.26 \mathrm{~s}$; $\mathrm{F}=1.62, P>0.05)$, or the number of vertical rears $(\mathrm{aCSF}=$ $30.67 \pm 3.99 ; \quad 0.5 \mathrm{pmol}=26.5 \pm 3.34 ; \quad \mathrm{F}=1.43, \quad P>0.05)$. Taken together, these data suggest that blockade of BLA D3Rs with the selective antagonists U99194 and GR103691 can produce anxiolytic effects without significant alterations of locomotor-related behaviors.

In a separate analysis, we analyzed data from 'miss' animals to further determine the contribution of the BLA to the behavioral measures. When comparing sham-treated to 'miss' animals, we found no significant difference between the two groups in time in the light side of the light/dark box $(P>0.05, \mathrm{~F}=1.56, t$-test) or time in the open arms of the plus maze $(P>0.05, \mathrm{~F}=4.84, t$-test $)$. Misses were typically located dorsal and lateral to the BLA (striatum and entorhinal cortex, respectively, not shown). This analysis suggests that the anxiolytic effect of the D3R antagonist microinjection is specific to intra-BLA delivery.

\section{LPC and Local GABAergic Synapses can be Functionally Distinguished}

Recent results suggest that DA-dependent signaling in the BLA specifically targets GABAergic transmission (Bissiere

Table 2 Effects of Intra-BLA U99194 Microinjection on Open-Field Behavior

\begin{tabular}{lcccc}
\hline & Sham & I.5 pmol & $\mathbf{5 . 0}$ pmol & Statistic $^{\mathbf{a}}$ \\
\hline No. of moves & $26.0 \pm 3.4$ & $27.6 \pm 3.4$ & $26.6 \pm 2.5$ & NS \\
Movement time (s) & $257.6 \pm 9.0$ & $254.0 \pm 9.5$ & $262.7 \pm 2.9$ & NS \\
Total distance (cm) & $|17| \pm 1 \mid 4$ & $1220 \pm 10 \mid$ & $1345 \pm 57$ & NS \\
Vertical rears & $20.1 \pm 4.4$ & $23.8 \pm 3.9$ & $29.1 \pm 3.3$ & NS
\end{tabular}

${ }^{\text {aD }}$ ata are expressed as mean \pm SEM and were analyzed with a standard one-way ANOVA. 'NS' = no significant differences between groups.

Table I Effects of Intra-BLA U99194 Microinjection in the Elevated Plus Maze

\begin{tabular}{|c|c|c|c|c|}
\hline & Sham & I.5 pmol & $5.0 \mathrm{pmol}$ & Statistic $^{a}$ \\
\hline Open-arm time (s) & $7.5 \pm 3.7$ & $41.7 \pm 5.5$ & $104.8 \pm 16.9^{*} * * * \# \#$ & $P<0.01$ \\
\hline Closed-arm time (s) & $208.3 \pm 22.8$ & $173.9 \pm 11.4$ & $106.6 \pm 16.4 * *, \# \#$ & $P<0.01$ \\
\hline Junction time (s) & $84.3 \pm 23.3$ & $84.5 \pm 8.1$ & $88.5 \pm 7.5$ & NS \\
\hline No. of open-arm entries & $0.8 \pm 0.4$ & $2.0 \pm 0.4$ & $6.9 \pm 0.9 * * *, \# \# \#$ & $P<0.001$ \\
\hline Percentage of open-arm entries & $7.2 \pm 3.0$ & $28.7 \pm 8.2^{*}$ & $50.1 \pm 5.1 * * * *, \#$ & $P<0.001$ \\
\hline No. of closed-arm entries & $6.2 \pm 2.7$ & $7.1 \pm 1.8$ & $6.6 \pm 0.7$ & NS \\
\hline
\end{tabular}

aData are expressed as mean \pm SEM and were analyzed with a standard one-way ANOVA. P-values indicate significant differences between column means. 'NS' = no

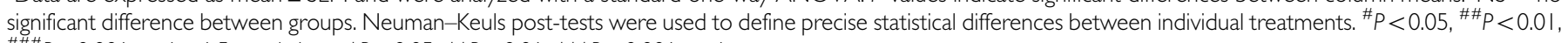
$\# \# P<0.00$ I vs the 1.5 pmol dose; $* P<0.05$, *** $P<0.01$, *** $P<0.001$ vs sham. 
et al, 2003; Kroner et al, 2005; Marowsky et al, 2005). However, BLA GABAergic neurons are represented by 'local' feedback interneurons scattered throughout the nucleus (McDonald et al, 2005) and 'islands' of feedforward interneurons scattered along the lateral/paracapsular border of the BLA (Fuxe et al, 2003; Marowsky et al, 2005). Anatomical data suggests that the local feedback interneurons synapse on the soma and proximal dendritic compartments of principal neurons (McDonald and Betette, 2001), whereas LPC feedforward interneurons synapse onto distal dendritic processes (Marowsky et al, 2005; Muller et al, 2007). This anatomical arrangement suggests that these synapses might be functionally independent. To test this, we preformed a synaptic 'collision' experiment (Szinyei et al, 2000; Xiang et al, 2002) using whole-cell patch-clamp electrophysiology of BLA principal neurons. When paired electrical stimuli are delivered to BLA GABAergic inputs using a long inter-stimulus interval $(250 \mathrm{~ms}$ in this case; Silberman et al, 2008), the second synaptic response is typically smaller than the first. This 'paired-pulse depression' is thought to reflect feedback inhibition by presynaptic autoreceptors (Silberman et al, 2009). If local and LPC GABAergic inputs are functionally distinct, the mechanisms controlling paired-pulse depression at one synapse should not affect the other. When stimulating either the local or the LPC GABAergic synapses (Figure 2a), paired electrical stimuli caused substantial inhibition of the second synaptic response relative to the first (Figure $2 b_{1}$ and $c$ ). Conversely, stimulation of one GABAergic input followed $250 \mathrm{~ms}$ later by stimulation of the other input caused no paired-pulse depression (Figure $2 b_{2}$ and $c ; n=7$ cells at each stimulation site or group). These data suggest that the GABAergic synapses from the two interneuron populations can be functionally separated by the placement of the stimulating electrode.

To further confirm that we can independently activate GABAergic synapses arising from these two interneuron populations, we employed BRL 37344, a selective $\beta 3$-adrenergic receptor agonist, which has recently been shown to robustly potentiate LPC GABAergic synapses without affecting local synapses (Silberman et al, 2010). We found that BRL $37344(10 \mu \mathrm{M})$ significantly potentiated the LPC GABA-IPSC $(39.93 \pm 8.24 \%$ from baseline, $n=6)$. In contrast, BRL 37344 did not significantly alter the local IPSC compared with baseline $(6.72 \pm 7.12 \%$ from baseline, $n=6, P<0.05$, $t$-test; data not shown). These pharmacological data provide further evidence that LPC and local GABAergic synapses can be independently activated using placement of the stimulating electrodes.

\section{D3-Like DA Receptors Modulate BLA GABAergic Transmission}

Given the anxiolytic effects of the D3R antagonists when injected into the BLA, we first examined the effects of D3Rlike activity on synaptic transmission within the BLA. The D3-selective agonist PD128907 (Audinot et al, 1998) significantly inhibited the amplitude of electrically evoked GABAergic IPSCs elicited from both the LPC and local synapses (Figure 3a). The inhibition of GABAergic transmission by $10 \mu \mathrm{M}$ PD128907 did not recover during an extensive washout period (Figure $3 \mathrm{~b}$ ). Despite this, the pipette resistance did not significantly change during the duration of these recordings. At time $=5 \mathrm{~min}$, series a

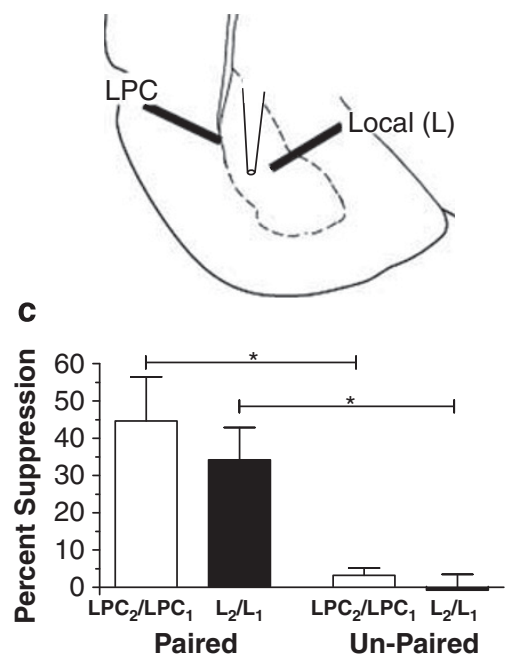

b $\quad$ Paired Stimulation Sites

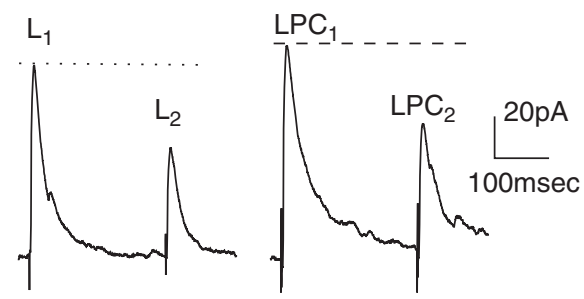

$b_{2}$ Un-paired Stimulation Sites

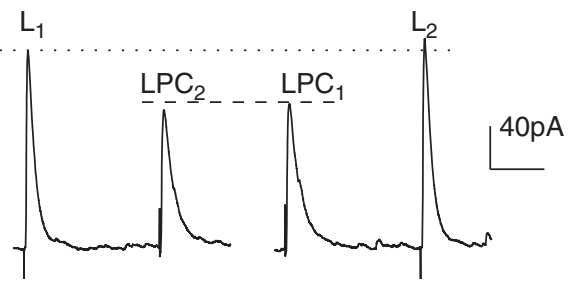

Figure $2 \gamma$-Aminobutyric acid (GABA)ergic synaptic responses from different basolateral amygdala (BLA) interneuron populations can be functionally distinguished. (a) Schematic diagram of the BLA indicating the approximate anatomical relationships between stimulating electrodes (black bars) placed near the external capsule to stimulate feedforward inhibitory interneurons (lateral paracapsular cells (LPC)) and within the nucleus to stimulate local feedback inhibitory interneurons (L). The recording electrode (hollow pipette) is placed between the stimulating electrodes. The coronal slice was adapted from Paxinos and Watson (1997). Sample traces illustrate paired-pulse depression of inhibitory postsynaptic current (IPSC) amplitude ( $b_{1} ; L_{2} / L_{1}$ and $\left.L P C_{2} / L P C_{1}\right)$ during a paired stimulation of the same anatomical site using an inter-stimulus interval of $250 \mathrm{~ms}$. Pronounced paired-pulse depression characterized both the LPC and local GABAergic synapses. In contrast, when these anatomical sites are stimulated consecutively ( $b_{2}$; un-paired stimulus), there was little pairedpulse depression. Both traces are from the same cell and exemplify the experimental approach of alternating stimulation sites to calculate the paired-pulse depression ratio. A graphical summary (c) of the percent suppression of the second response compared with the first response during the PP250 when a single anatomical site is stimulated ('paired'; $n=7$ cells at each stimulation site) compared with sequential stimulation of the two different stimulation sites ('un-paired'; $n=7$ in each group). $* P<0.05$, $t$-test between the different stimulation sites. 

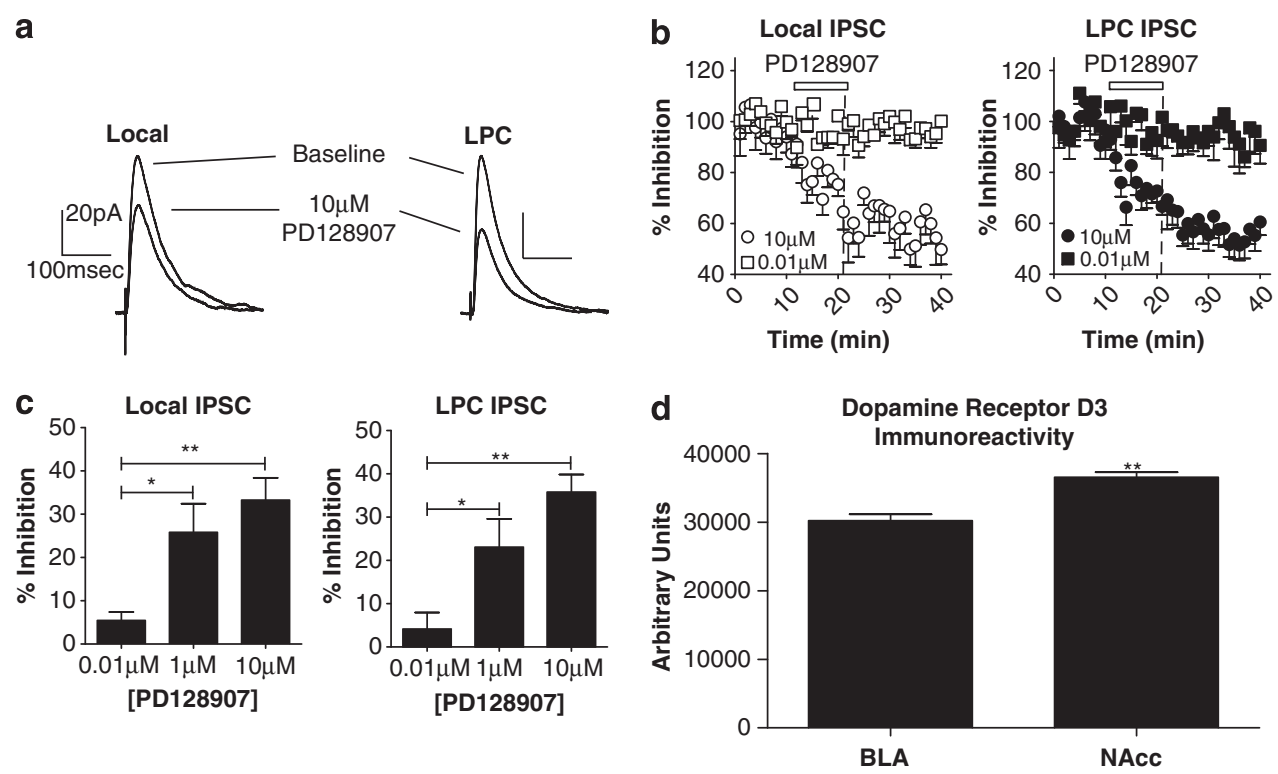

Figure 3 A D3 dopamine receptor agonist suppresses $\gamma$-aminobutyric acid (GABA)ergic synaptic transmission at both local (left) and lateral paracapsular cell (LPC) (right) interneuron synapses in the basolateral amygdala (BLA). Exemplar traces (a) illustrate the robust modulation of GABAergic inhibitory postsynaptic currents (IPSCs) by the D3R agonist PDI28907. The effects of $10 \mu \mathrm{M}$ PDI28907 (b) were slow onset and did not appear to be reversible during a prolonged washout period ( $n=6$ cells for both 0.01 and I $0 \mu$ M PDI 28907 at the local synapses, $n=5$ for $0.01 \mu M$ and $n=9$ for $10 \mu M$ at the LPC synapses). Regardless, inhibition of both local and LPC GABAergic responses by PDI 28907 was concentration dependent (c), measured at the end of the drug application period indicated by the dashed vertical line in (b). Averaged data in bar graphs represents data from the last 5 min (averaged into I min bins) of the drug application. $* P<0.05$ for comparison between $0.01 \mu \mathrm{M}$ and I $\mu \mathrm{M}$; **P<0.0I between $0.01 \mu \mathrm{M}$ and $10 \mu \mathrm{M}$. (d) Robust immunoreactivity from BLA samples $(n=4)$ using a specific D3R antibody. ** $P<0.0$ I. Samples from nucleus accumbens (NAcc) $(n=4)$ had a significantly stronger immunoreactive signal. Bands from western blots are shown below the corresponding column in the bar graph.

resistance was $24.4 \pm 3.1 \mathrm{M} \Omega$, and at time $=35 \mathrm{~min}$, it was $24.8 \pm 3.0 \mathrm{M} \Omega(P>0.05$, paired $t$-test $)$. These data together suggest that PD128907 modulation of LPC and local GABAergic synaptic responses was irreversible. When measured at the end of the drug application period (dashed line, Figure 3b), $10 \mu \mathrm{M}$ PD128907 inhibited LPC IPSCs by $35.7 \pm 4.1 \%(n=9)$ and local IPSCs by $33.3 \pm 5.2 \%(n=6)$. PD128907 $(1 \mu \mathrm{M})$ inhibited LPC GABAergic responses by $23.0 \pm 6.6 \%(n=6)$ and local responses by $25.8 \pm 6.6 \%$ $(n=5)$. And, $10 \mathrm{nM}$ PD128907 inhibited LPC synapses by $4.1 \pm 3.9 \%(n=5)$ and local synapses by $5.5 \pm 1.9 \%(n=6)$. One-way ANOVA analysis of these data found that the magnitude of PD128907 inhibition was significantly concentration dependent (Figure $3 \mathrm{c})$ at both the local $(\mathrm{F}=8.3$, $P<0.01)$ and LPC synapses $(\mathrm{F}=10.9, P<0.001)$, with the modulation by both the 1 and $10 \mu \mathrm{M}$ being significantly greater than the $10 \mathrm{nM}$ concentration $\left({ }^{\star} P<0.05\right.$, ${ }^{* *} P<0.01$; Newman-Keuls post-test).

This D3-like modulation of GABAergic transmission within the BLA suggests that the D3 DA receptors are expressed in this brain region. To confirm this, we used a D3R-specific antibody with no known cross-reactivity with D2 DA receptors and found robust D3R-like immunoreactivity from BLA samples (Figure $3 \mathrm{~d}, n=4$ ). We compared BLA D3R immunoreactivity with that found in the NAcc $(n=4)$, as it has been shown to have high expression of D3Rs (Guitart-Masip et al, 2006; Le Foll et al, 2005). Consistent with this, we found significantly higher levels of D3-like immunoreactivity in the NAcc compared with the BLA $(\mathrm{F}=1.57, P<0.01, t$-test $)$. Along with the
PD128907 modulation, these biochemical data suggest that D3-like DA receptors can be found within the BLA.

To confirm the receptor responsible for PD128907 modulation, we employed the two D3 receptor antagonists used in our behavioral experiments along with a highly potent D2-selective antagonist. In the presence of U99194, PD128097 inhibited local synapses by only $5.4 \pm 7.6 \%$ (Figure $4 \mathrm{e}, n=6$ ) compared with $33.3 \pm 5.2 \%$ inhibition with PD128907 alone ( $n=9$, data from Figure $3 c$; one-way ANOVA, $F=5.58$ (Newman-Keuls $P<0.05)$ ). When slices were pretreated with GR103691 (Figure 4a and b), PD128907 inhibited the local synapses by $8.9 \pm 5.6 \%(n=6$; one-way ANOVA, Newman-Keuls $P<0.05)$. In contrast, the D2R antagonist, L741626, only slightly diminished the PD128907mediated inhibition to $26.8 \pm 4.4 \%$ (Figure $4 \mathrm{c}$ and $\mathrm{d} ; n=5$, one-way ANOVA, $P>0.05)$. Similarly, at LPC synapses, PD128907 + U99194 (Figure 4e, $n=6$ ) inhibited GABAergic responses by $12.5 \pm 4.6 \%$ compared to $35.7 \pm 4.1 \%$ with PD128907 alone (one-way ANOVA, F=11.26 (NewmanKeuls $P<0.01)$ ). GR103691 almost completely blocked the effect of PD128907 at LPC synapses (Figure 4a and b), only permitting PD128907 to inhibit $1.8 \pm 3.5 \%(n=6$; one-way ANOVA, $F=8.59$ (Newman-Keuls $P<0.001)$ ). As with the local synapses, L741626 could not block the inhibitory effect of PD128907 at LPC synapses (Figure $4 \mathrm{c}$ and d; $27.1 \pm 5.9 \%$, $n=6, P>0.05$ compared with PD128907).

U99194 $(3 \mu \mathrm{M})$ alone did not alter synaptic responses at either the LPC $(2.9 \pm 6.4 \%$ inhibition, $n=5)$ or the local $(0.0 \pm 7.4 \%$ inhibition, $n=5)$ GABAergic synapses. GR103691 $(1 \mu \mathrm{M})$ also did not affect synaptic responses at 

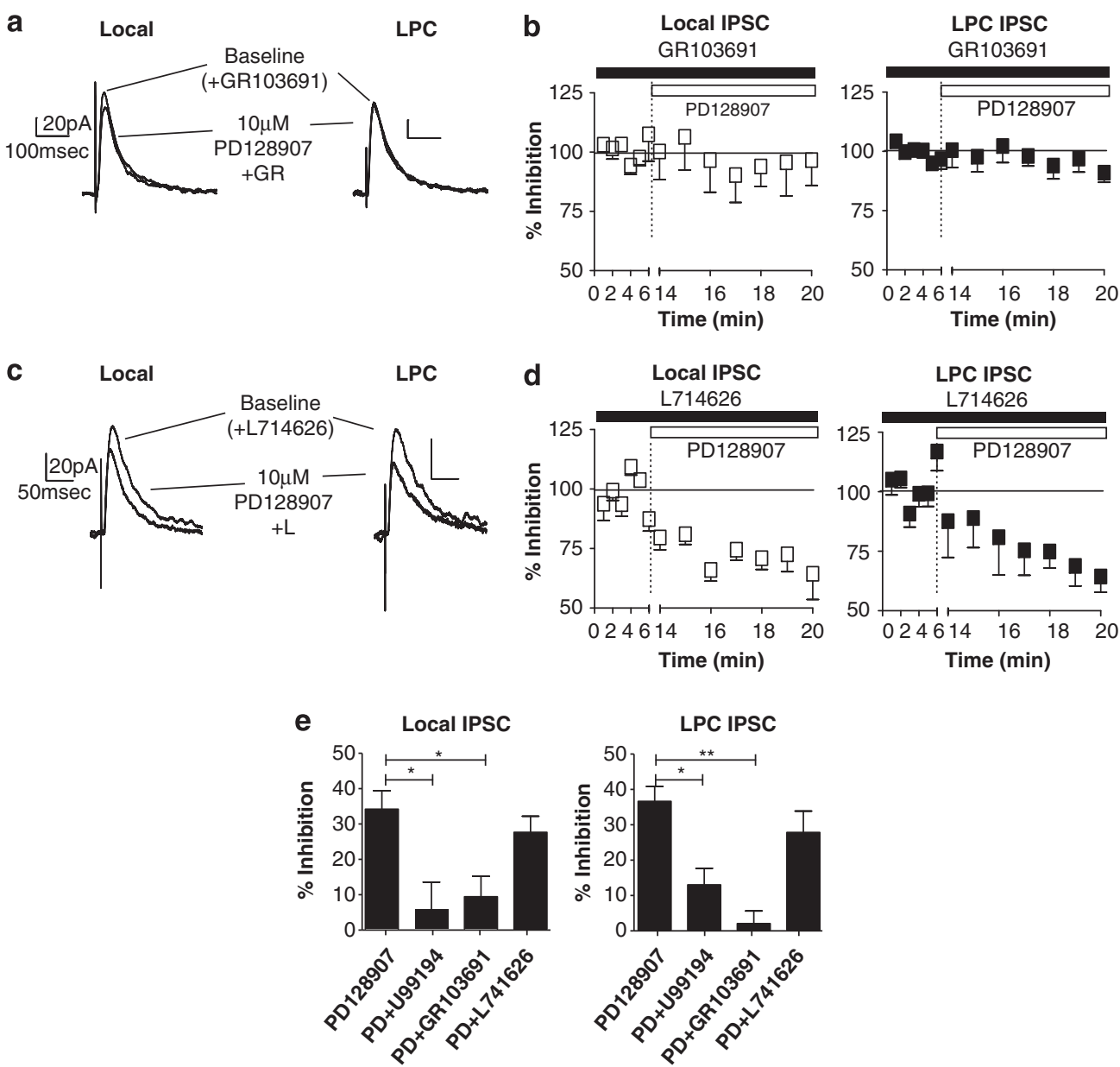

Figure 4 Dopamine D3, but not D2, receptor antagonists attenuate the effect of PDI 28907 at both local and lateral paracapsular cell (LPC) interneuron synapses in the basolateral amygdala (BLA). Exemplar traces (a) show that PDI 28907 has little to no effect on $\gamma$-aminobutyric acid (GABA)ergic inhibitory postsynaptic currents (IPSCs) when pretreated with the selective D3R antagonist GRI0369I. With GRI0369I on the slice, PDI28907 (I0 $\mu$ M) had no inhibitory effect on GABAergic IPSCs following a 14 min wash (b; $n=6$ for both local and LPC synapses). Exemplar traces (c) show that in slices pretreated with the selective D2R antagonist L7|4626, PDI28907 robustly modulated GABAergic IPSCs. In contrast to GRI0369I, with L7I4626 on the slice, PDI28907 (I0 $\mu \mathrm{M})$ inhibited GABAergic IPSCs following a 14 min wash (d; $n=5$ for local and $n=6$ for LPC synapses). PDI 28907 (I0 $\mu$ M) inhibition (e) was significantly attenuated by the D3R antagonists U99|94 ( $3 \mu \mathrm{M})$ and GRI0369I (I $\mu \mathrm{M}$ ), but not by the D2R antagonist L74I626 (50 nM). Averaged data in bar graphs represents data from the last 5 min (averaged into I min bins) of steady drug effect. *P $<0.05$ between PD and PD + U99।94 groups; *** $P<0.0$ l between PD and PD + GR for LPC IPSC.

LPC $(-3.7 \pm 2.8 \%$ inhibition, $n=6)$ or local $(6.2 \pm 5.5 \%$ inhibition, $n=6)$ synapses. Likewise, $50 \mathrm{nM}$ L741616 did not alter synaptic transmission at LPC $(2.4 \pm 7.1 \%$ inhibition, $n=6)$ or local $(8.4 \pm 11.6$ inhibition, $n=6)$ synapses. These data together support the hypothesis that D3Rs, but not D2-like, modulate GABAergic synapses at two BLA interneuron populations.

\section{D3Rs Modulate BLA GABAergic Synapses via both Post- and Presynaptic Mechanisms}

To examine the mechanism responsibe for the D3-like modulation of the BLA GABAergic system, we examined the effects of PD128907 on paired-pulse facilitation at LPC and local GABAergic synapses. Using the dual stimulation protocol (Figure 5), we found that PD128907 had no significant effect on PPRs from LPC synapses (Figure $4 \mathrm{c}$ and d; PP50: baseline $=0.07 \pm 0.19, \quad$ PD128907 $=0.02 \pm 0.19$; PP250: baseline $=-0.52 \pm 0.03, \quad$ PD128907 $=-0.50 \pm 0.09$, $n=6, \quad P>0.05$, paired $t$-test at both inter-stimulus intervals). However, PD128907 increased the PPRs at the 50 -ms stimulus interval at the local synapses (Figure $4 \mathrm{a}$ and b; PP50: baseline $=0.05 \pm 0.15, \quad$ PD128907 $=0.18 \pm 0.16$; $n=7, P<0.05$, paired $t$-test), but did not significantly alter the ratio at the $250-\mathrm{ms}$ stimulus interval (baseline $=$ $-0.24 \pm 0.15, \quad$ PD128907 $=-0.17 \pm 0.10 ; \quad n=7, \quad P>0.05$, paired $t$-test). PD128907 inhibition of the initial synaptic response of the paired stimuli was $28 \pm 2 \%$ at local synapses and $37 \pm 4 \%$ at LPC synapses in this experiment. These data suggest that D3R modulation of GABAergic transmission might involve presynaptic mechanisms at the local feedback synapses, but not at the feedforward LPC synapses.

To test this hypothesis, we measured the effect of PD128907 on miniature spontaneous IPSCs using $1 \mu \mathrm{M}$ TTX in the extracellular solution. Recent pharmacological evidence suggests that mIPSCs recorded from principal BLA neurons arise primarily from local, but not LPC synapses (Silberman et al, 2009). We therefore recorded mIPSCs before and after the addition of $10 \mu \mathrm{M}$ PD128907 to the extracellular solution (Figure 6a). PD128907 significantly 
a

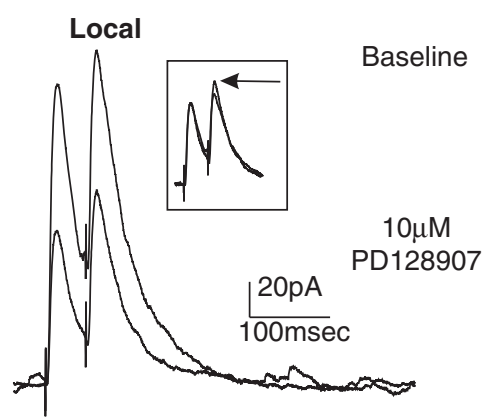

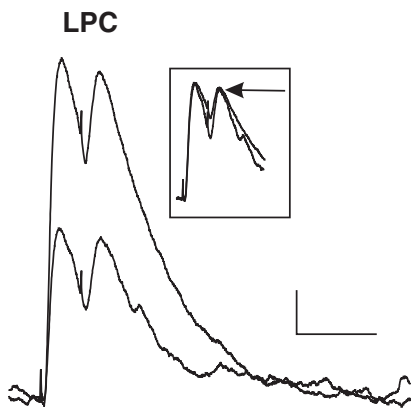
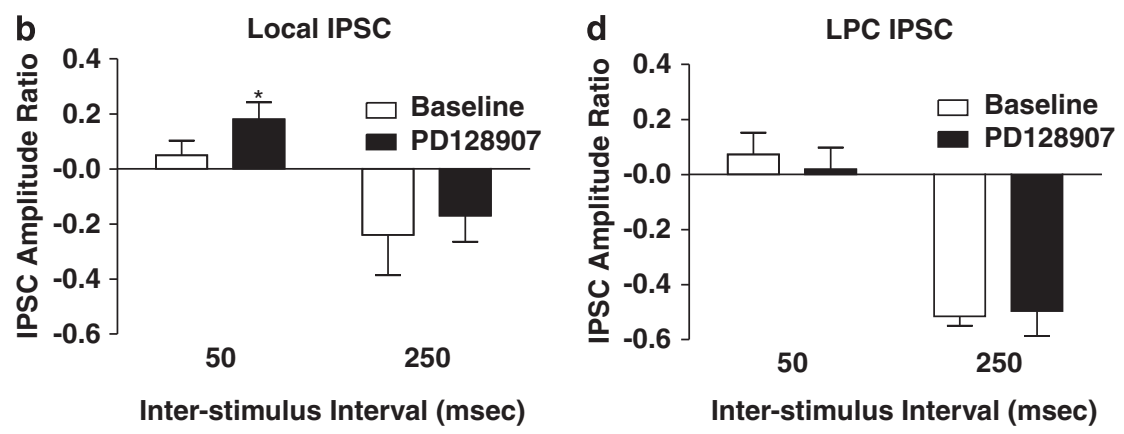

Figure 5 Basolateral amygdala (BLA) D3-like receptors (D3Rs) differentially modulate $\gamma$-aminobutyric acid (GABA)ergic release at BLA local and lateral paracapsular cell (LPC) GABAergic synapses. Paired electrical stimuli were delivered to either local (left, a) or LPC (right, c) GABAergic synapses using either 50- or 250-ms (not shown) inter-stimulus intervals. In the insets, the amplitude of the first synaptic response in the presence of PDI28907 has been normalized to the baseline inhibitory postsynaptic current (IPSC) amplitude to illustrate the relative effects of the D3 receptor agonist on the two synaptic responses. At the 50-ms stimulus interval, the ratio of the IPSC amplitude generated from the second stimulus relative to the first stimulus was significantly altered by PDI 28907 at local synapses (b; $n=7$, $* P<0.05$, $t$-test), but not at LPC synapses $(d ; n=6, P>0.05)$. The IPSC amplitude ratios were not altered by PDI28907 at the 250-ms stimulus interval at either synapse.

reduced the mIPSC interevent interval (Figure 6c) from $226 \pm 20$ to $280 \pm 29 \mathrm{~ms}$ ( $n=6 ; \quad P<0.05$, paired $t$-test). PD128907 also significantly inhibited mIPSC amplitude (Figure 6b) in these same neurons, reducing amplitude from $25.2 \pm 2.0$ to $17.3 \pm 0.7 \mathrm{pA} \quad(P<0.01$, paired $t$-test $)$. The mIPSC frequency data may be consistent with the pairedpulse data and suggests that D3Rs reduce GABA release at the local synapses. However, the mIPSC amplitude data, along with the absence of any effect on PPRs at the LPC synapses, suggests that D3Rs may also modulate local and LPC synapses via a postsynaptic mechanism as well.

It has been previously reported that $\mathrm{D} 3 \mathrm{R}$ activation can increase $\mathrm{GABA}_{\mathrm{A}} \mathrm{R}$ endocytosis in the hippocampus (Hammad and Wagner, 2006; Swant et al, 2008) and the NAcc (Chen et al, 2006). To test whether similar mechanisms are responsible for D3R postsynaptic modulation in the BLA, we dialyzed cells with either a dynamin-inhibitory peptide ('P4', Gln-Val-Pro-Ser-Arg-Pro-Asn-Arg-Ala-Pro; $50 \mu \mathrm{M}$ ) or with a control 'scrambled' peptide (Gln-Pro-Pro-Ala-Ser-Asn-ProArg-Val-Arg; $50 \mu \mathrm{M}$ ) added to the intracellular recording solution. The 'P4' peptide is analogous to the region in dynamin that acts as a binding site for amphiphysin (Grabs et al, 1997) and can block clathrin-dependent internalization of $\mathrm{GABA}_{\mathrm{A}}$ receptors (Kittler et al, 2000). Following opening the cell membrane in the whole-cell configuration and a brief 10 min period to allow distribution of a peptide throughout the intracellular compartment, we collected baseline-evoked responses for $7 \mathrm{~min}$ and subsequently measured the modulation of local and LPC-evoked IPSCs by the application of PD128907 $(1 \mu \mathrm{M})$. In different groups of cells, we found that intracellular dialysis with the 'P4' peptide attenuated
PD128907 inhibition of GABA-IPSCs relative to the control peptide. PD128907 inhibited 'local' IPSCs (Figure 7a) by $23.1 \pm 3.7 \%(n=8)$ with the control peptide in the intracellular solution, but only by $5.5 \pm 2.6 \%(n=8, P<0.01, t$-test $)$ when BLA neurons were perfused with the 'P4' peptide. Similarly at the LPC synapses, 'P4' peptide significantly reduced the inhibition by PD128907 (Figure 7a) from $30.3 \pm 4.4 \% \quad(n=8$ with control peptide $)$ to $4.6 \pm 4.4 \%$ $(n=7, P<0.01)$. These data, along with the irreversible inhibition by PD128907 (Figure 3), suggest that D3-like modulation of BLA GABAergic responses involves dynamindependent process, presumably related to the internalization of $\mathrm{GABA}_{\mathrm{A}}$ receptors by $\mathrm{D} 3$-mediated signaling. To test this, we reasoned that PD128907 modulation should NOT be reversed with a subsequent application of an antagonist. In a different set of cells, we established a stable PD128907 inhibition of GABA-IPSCs and then applied U99194 for 30 min. We found that PD128907 inhibition could not be reversed by the antagonist at either local (Figure 7c, PD128907 $=28.22 \pm 3.31 \%$ baseline, U99194 $=38.97 \pm 6.43 \%$ baseline, $n=4$ ) or LPC synapses (Figure 7d, PD128907 = $33.75 \pm 5.34 \%$ baseline, U99194 $=42.94 \pm 7.03 \%$ baseline, $n=4)$. These data are consistent with a long-lasting D3-like modulation related to dynamin-mediated endocytosis of postsynaptic $\mathrm{GABA}_{\mathrm{A}}$ receptors.

\section{D3Rs Do Not Modulate BLA Glutamatergic Synaptic Transmission}

To examine any potential involvement of glutamate synaptic transmission with the anxiolytic effects of D3 

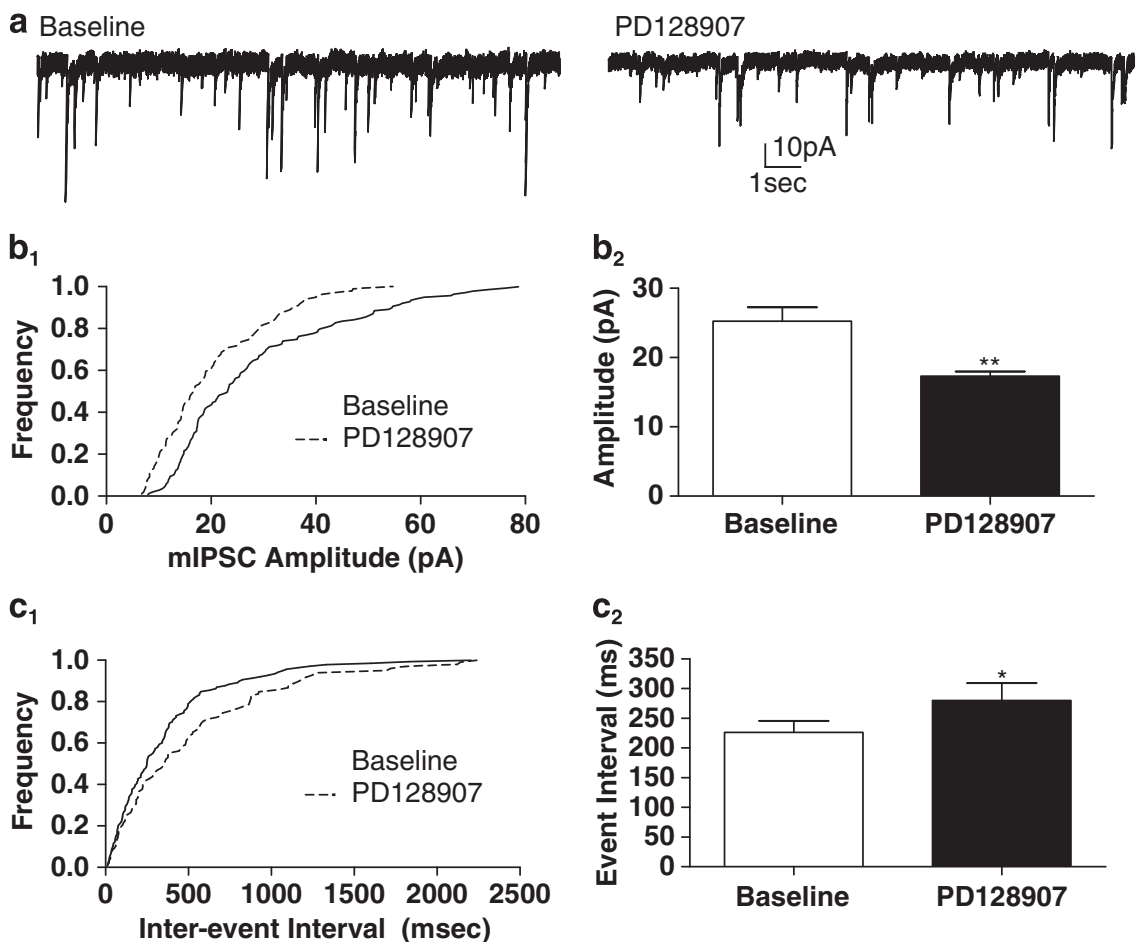

Figure 6 The D3 receptor agonist PD 28907 alters both the frequency and the amplitude of spontaneous, tetrodotoxin-resistant inhibitory postsynaptic currents (IPSCs). Miniature IPSCs (mIPSCs) (a) were recorded in the presence of tetrodotoxin and high concentrations of intracellular chloride (see Materials and Methods). For an exemplar cell, PDI 28907 significantly shifted the cumulative probability distribution of mIPSC amplitude to the left $\left(b_{1} ; \mathrm{KS}\right.$ statistic $\left.=0.23, P<0.0 \mathrm{I}\right)$ and the mIPSC interevent interval to the right $\left(c_{1} ; \mathrm{KS}=0.18, P<0.05\right)$. Summary graphs across all cells $(n=5)$ shows that PDI 28907 significantly inhibited both mIPSC amplitude ( $b_{2} ; * * P<0.0$ I, paired $t$-test) and mIPSC frequency $\left(c_{2} ; * P<0.05\right.$, paired $t$-test).

antagonist microinjection, we measured the effects of $10 \mu \mathrm{M}$ PD128907 on pharmacologically isolated, AMPA-mediated EPSCs evoked by 'local' electrical stimuli. PD128907 inhibited EPSC amplitude by only $3.8 \pm 2.9 \% \quad(P>0.05$, paired $t$-test, data not shown). Likewise, the D3R antagonist U99194 did not alter EPSC amplitude (1.0 $\pm 3.9 \%$ facilitation; $P>0.05$, paired $t$-test, not shown) under our recording conditions. These data suggest that D3R activation specifically modulates GABAergic, but not glutamatergic synaptic transmission in the BLA.

\section{DISCUSSION}

This study provides convincing evidence that BLA DA D3Rs play a prominent role in modulating anxiety-like behaviors. These data are consistent with previous findings, which showed that D3 knockout mice were less 'anxious' than wild-type controls, spending significantly more time in the open arms of an elevated plus maze and in the center of an open field (Steiner et al, 1997). In addition, Phillips et al (2002) showed that microinjections of the D3R antagonist nafadotride into the rat amygdala reduced taste-related associative learning in isolation reared animals. Our data compliment and extend these findings to specifically implicate BLA D3Rs in the modulation of innate anxietylike behaviors. Specifically, we found that rats microinjected with low doses of either U99194 or GR103691 spent significantly more time on the light side of a light/dark box compared with vehicle-injected animals. Likewise,
U99194- and GR103691-injected animals spent significantly more time on the open arms of an elevated plus maze than the closed arms compared with vehicle-injected animals. Importantly, the effects of the D3R antagonists on anxietylike behavior were not due to significant alterations in locomotion as there were no significant differences in movement time or distance measured in an open field. Because U99194 has only a 14-fold higher affinity for D3R over D2R, we also tested a more selective D3R antagonist, GR103691, which has a 60-fold higher affinity for D3R over D2R (Audinot et al, 1998). Given that the use of both antagonists resulted in very similar modulation of BLAmediated behaviors, our data strongly suggest that activation of BLA D3Rs by the novel environments represented by the light/dark box and the elevated plus maze helps to increase anxiety-like behavior in these apparati. Both novel environmental cues (Inglis and Moghaddam, 1999) and conditioned cues (Yokoyama et al, 2005) increase extracellular DA levels in the BLA, presumably by activation of VTA DA neurons, which provide the majority of dopaminergic input into this brain region (Carter and Fibiger, 1977). This suggests that exposure to the light/dark box or elevated plus maze would increase DA levels in the BLA and increase the expression of anxiety-like behaviors at least in part by activating D3Rs.

Importantly, our electrophysiological findings illustrate the potential physiological mechanism by which DA might influence anxiety-like behavior. Specifically, we show that D3R activation suppresses inhibitory GABAergic synapses, but not glutamatergic synapses, onto BLA projection 


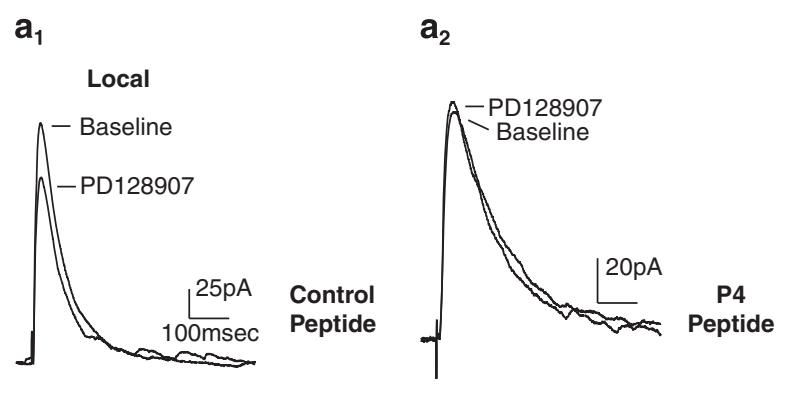

$\mathbf{b}_{1}$

$b_{1} \quad$ LPC

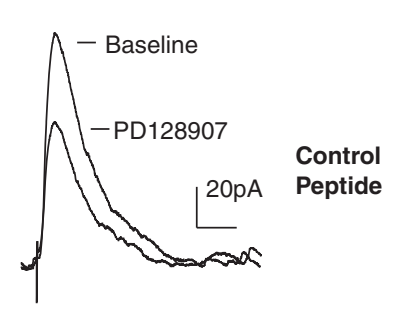

$\mathbf{a}_{3}$

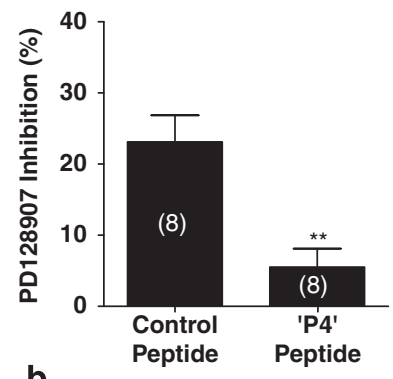

$\mathbf{b}_{2}$

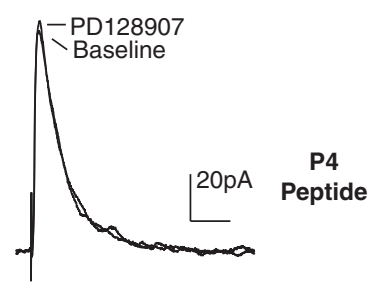

$\mathbf{b}_{3}$

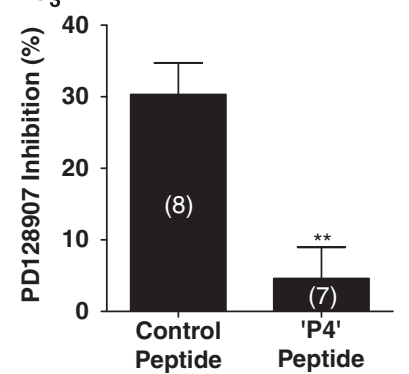

$\mathbf{C}_{1}$
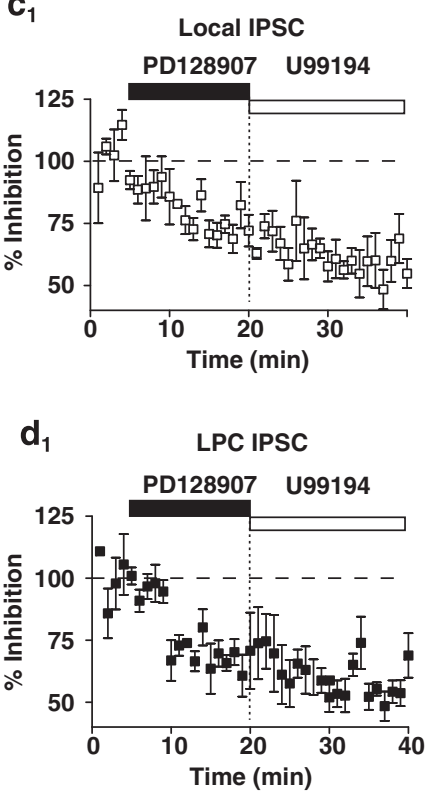

$\mathrm{C}_{2} \quad$ Local IPSC

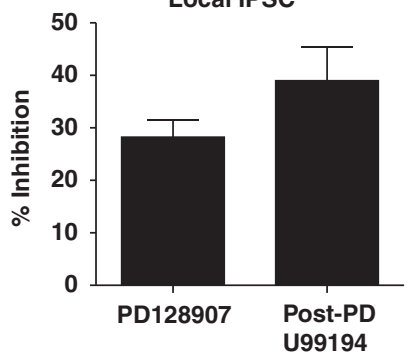

$d_{2}$

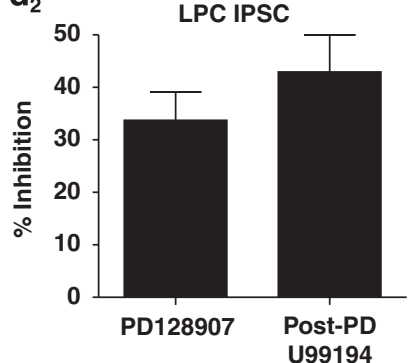

Figure 7 D3-like receptor (D3R) modulation of basolateral amygdala (BLA) $\gamma$-aminobutyric acid (GABA)ergic inhibitory postsynaptic currents (IPSCs) is dependent on a dynamin-mediated process that is not readily reversible. At both local (left, a) and lateral paracapsular cell (LPC) (right, b) inhibitory synapses, I $\mu$ M PDI28907 substantially suppressed the amplitude of electrically evoked responses $\left(a_{1}\right.$ and $\left.b_{1}\right)$ when a control 'scramble' peptide was included in the intracellular recording solution. In a separate group of neurons, intracellular perfusion with a peptide (P4) that disrupts dynamin-mediated endocytosis disrupted PDI 28907 inhibition at both local $\left(a_{2}\right)$ and LPC GABAergic synapses $\left(b_{2}\right)$. Summary graphs of these data for both local $\left(a_{3}\right)$ and LPC $\left(b_{3}\right)$ responses show that the P4 peptide significantly attenuated PDI 28907 inhibition relative to recordings with the control peptide $(* * P<0.01$, $t$-test). The numbers of cells in each group are indicated within parentheses. In a separate experiment, the inhibitory effect of PDI 28907 was not reversed by a 30 min application of U99194 at both local $\left(c_{1}\right.$ and $\left.c_{2}\right)$ and LPC $\left(d_{1}\right.$ and $\left.d_{2}\right)$ synapses following the agonist application. Summary graphs for these data indicate that U99194 had no significant effect on the inhibitory effect of PDI 28907 ( $P>0.05, t$-test).

neurons. The GABAergic system in the BLA is comprised of at least two populations of interneurons that differ with respect to their forms of inhibition (feedforward and feedback) as well as their neuroanatomical placements (Marowsky et al, 2005; McDonald and Betette, 2001; McDonald et al, 2005; Muller et al, 2007). This paper and work by others have shown that GABAergic synapses arising from these populations are functionally independent
(Silberman et al, 2008) and experimentally separable merely by the placement of the stimulating electrode. Similar experimental manipulations have also been shown in the hippocampus where one stimulating electrode was placed in stratum lacunosum-moleculare (distal stimulation) and a second electrode in the stratum radiatum (proximal stimulation) to activate two independent GABAergic interneuron populations/pathways converging onto the same 
glutamatergic pyramidal neuron, albeit at distinct anatomical compartments (dendritic - distal; somatic - proximal) (Weiner et al, 1997; Wu et al, 2005). Furthermore, we and others have now shown that these two populations can also be pharmacologically manipulated using selective adrenergic drugs (Silberman et al, 2010). These findings not only validate that these two GABAergic interneuron populations are functionally independent, but also opens up the doors to future research on other systems that may exclusively target one of these populations $v s$ the other.

Our data suggest that DA release within the BLA activates, among others, D3Rs, which inhibit GABAergic transmission at both feedforward and feedback inhibitory interneurons. Yet, it is worth noting that while we did not observe any significant effect of the D3R antagonists alone on GABAergic transmission, we did find a robust effect of the D3R antagonist on anxiety-like behavior. These data can be interpreted by the mere fact that the DA circuitry is intact in vivo, but not in vitro. Specifically, as discussed previously, DA levels in the BLA are robustly elevated in vivo following exposures to novel environments (Inglis and Moghaddam, 1999; Yokoyama et al, 2005), presumably resulting in a phasic activation of D3Rs (in addition to other DA receptors that will be later discussed). In contrast, in our in vitro slice preparation, endogenous DA levels are apparently not significantly elevated with the electrical stimulation that we use, at least as suggested by the absence of any significant effect of the antagonists themselves. However, stimulated DA released has been previously measured in the BLA following much stronger electrical stimulations (Jones et al, 1994). Regardless, the D3R antagonists only function to prevent an exogenous D3R agonist, such as PD128907, under our recording conditions.

The effects of D3R modulation also appear to differ between these GABAergic populations. Although PD128907 inhibits both local feedback and LPC feedforward IPSCs by a dynamin-dependent mechanism, paired-pulse data and measures of spontaneous TTX-resistant IPSCs suggest that D3Rs may also suppress presynaptic GABAergic function at synapses from local interneurons. However, interpretation of the mIPSC frequency data is confounded by the significant PD128907 modulation of mIPSC amplitude. Regardless, any direct presynaptic effect on local interneurons must be relatively modest given that the $\mathrm{P} 4$ dynamin inhibitory peptide suppressed the vast majority of PD128907 inhibition at local synapses. A major role for D3Rs expressed by projection neurons is consistent with the neuroanatomical data, which suggests that tyrosine hydroxylase-positive $\left(\mathrm{TH}^{+}\right)$terminals contact a relatively limited population of local GABAergic interneurons (Pinard et al, 2008), whereas over $90 \%$ of the $\mathrm{TH}^{+}$terminals in the BLA make contacts with the principal glutamatergic neurons (Muller et al, 2009) from which our recordings were made. The relative density of $\mathrm{TH}^{+}$terminals found associated with the feedforward LPC GABAergic neurons has not been measured directly. The absence of any significant presynaptic effect by PD128907 at LPC synapses might suggest a minimal role for dopaminergic modulation at these cells as well. However, recent studies have uncovered robust D1 receptor modulation of both local feedback (Kroner et al, 2005) and LPC feedforward (Marowsky et al, 2005) GABAergic interneurons. Given that BLA D1 receptors strongly modulate drug-seeking (Berglind et al, 2006; Gremel and Cunningham, 2009) and anxiety-related behaviors (de la Mora et al, 2005), one should not minimize potential contributions by dopaminergic terminals onto BLA GABAergic interneurons.

The postsynaptic cellular mechanisms mediating the majority of D3-like inhibition of BLA GABAergic transmission seems to involve the activation of dynamin-dependent signaling pathways. This is consistent with recent data showing D3R-mediated, dynamin-dependent inhibition of $\mathrm{GABA}_{\mathrm{A}}$ receptors in the NAcc (Chen et al, 2006) and the hippocampus (Hammad and Wagner, 2006; Swant et al, 2008). In both brain regions, D3 receptor activation is believed to reduce the activity of protein kinase A via inhibition of adenylyl cyclase. This ultimately decreases the phosphorylation of $\mathrm{GABA}_{\mathrm{A}}$ subunits making the receptor complex a substrate for clathrin-mediated endocytosis (Chen et al, 2006). Although we did not specifically examine PKA signaling pathways in this study, the dependence on dynamin-mediated processes strongly suggests a common mechanism for D3R-mediated decreases in GABAergic synaptic transmission in three distinct brain regions.

Despite our findings that D3Rs modulate BLA GABAergic transmission, we cannot rule out a direct modulatory effect of D3Rs on the principal neurons themselves. We did not observe any consistent D3-dependent modulation of principal neuron membrane properties, like changes in resting current or alterations in series resistance. However, our recording conditions, particularly loading the intracellular compartment with cesium and using whole-cell voltage clamp, would tend to minimize our ability to measure such phenomena. D2Rs can increase the excitability of principal neurons in other brain regions. For example, the D2/D3 agonist quinpirole increases spontaneous action potential frequency of glutamatergic subthalamic nuclei neurons by reducing calcium entry through voltage-gated calcium channels and subsequently suppressing calcium-dependent potassium currents (Ramanathan et al, 2008). In contrast, quinpirole does not appear to appreciably alter BLA principal neuron excitability (Kroner et al, 2005). Furthermore, our data complement the findings by Kroner et al (2005) and clearly indicate that the effects of PD128907 are not mediated through D2Rs, given that the highly selective D2R antagonist L714626 was unable to attenuate the effects of PD128907 at either local or LPC synapses. Nevertheless, any direct effects of D3Rs on BLA principal neuron membranes cannot be ruled out.

Although we did not investigate the effects of exogenous DA on GABAergic transmission within the BLA, the variety of receptor-specific studies suggest that any effects of endogenous neurotransmitter in this brain region are likely to be complex. GABAergic inputs arising from lateral paracapsular interneurons are suppressed by both D3Rs - but not D2R (this study) - and D1R (Marowsky et al, 2005) activation. This suggests that DA itself would suppress LPC neurons and would presumably reduce feedforward inhibition of the BLA. This robust, multi-faceted suppression of BLA feedforward inhibition can be contrasted with a primarily post-synaptic D3R inhibition and a 'presynaptic' D1R facilitation (Kroner et al, 2005; Marowsky et al, 2005) of local feedback GABAergic function. Changes in the relative expression or function of these different DA 
receptors may therefore significantly alter BLA function and contribute to the pathophysiology of different disorders, such as drug and alcohol abuse (Di Ciano, 2008; Le Foll et al, 2005; See et al, 2001; Vengeliene et al, 2006). Regardless, the spatial and temporal character of DA release in the BLA is likely to ultimately modulate the complexities associated with DA modulation of BLA output during an environmental stimulus or stressor.

In summary, we show that BLA DA D3Rs can help modulate the expression of anxiety-like behaviors. We also show that the most likely neurobiological mechanism controlling this process involves a long-lasting, postsynaptic, dynamin-dependent downregulation of GABAergic control over BLA principal neurons. This downregulation occurs at both feedforward LPC and local feedback inhibitory synapses. Overall, this dopaminergic modulation has the potential to tightly regulate the output from the BLA to downstream projection areas.

\section{ACKNOWLEDGEMENTS}

We thank the assistance of Drs Jeff Weiner and Sara Jones for their advice and helpful discussions. This work was funded by National Institutes of Health/National Institute on Alcohol Abuse and Alcoholism Grants R01 AA01445, U01 AA016671, P01 AA017056, and F31 AA017576 (MRD).

\section{DISCLOSURE}

The authors declare no conflict of interest.

\section{REFERENCES}

Audinot V, Newman-Tancredi A, Gobert A, Rivet JM, Brocco M, Lejeune $\mathrm{F}$ et al (1998). A comparative in vitro and in vivo pharmacological characterization of the novel dopamine D3 receptor antagonists (+)-S 14297, nafadotride, GR 103,691 and U 99194. J Pharmacol Exp Ther 287: 187-197.

Berglind WJ, Case JM, Parker MP, Fuchs RA, See RE (2006). Dopamine D1 or D2 receptor antagonism within the basolateral amygdala differentially alters the acquisition of cocaine-cue associations necessary for cue-induced reinstatement of cocaineseeking. Neuroscience 137: 699-706.

Bissiere S, Humeau Y, Luthi A (2003). Dopamine gates LTP induction in lateral amygdala by suppressing feedforward inhibition. Nat Neurosci 6: 587-592.

Camacho-Ochoa M, Walker EL, Evans DL, Piercey MF (1995). Rat brain binding sites for pramipexole, a clinically useful D3-preferring dopamine agonist. Neurosci Lett 196: 97-100.

Carter DA, Fibiger HC (1977). Ascending projections of presumed dopamine-containing neurons in the ventral tegmentum of the rat as demonstrated by horseradish peroxidase. Neuroscience 2 : 569-576.

Chen G, Kittler JT, Moss SJ, Yan Z (2006). Dopamine D3 receptors regulate $\mathrm{GABAA}$ receptor function through a phospho-dependent endocytosis mechanism in nucleus accumbens. J Neurosci 26: 2513-2521.

Davis M (2000). The role of the amygdala in conditioned and unconditioned fear and anxiety. In: Aggleton JP (ed). The Amygdala: A Functional Analysis. Oxford Press: New York. pp 213-288.

de la Mora MP, Cardenas-Cachon L, Vazquez-Garcia M, Crespo-Ramirez M, Jacobsen K, Hoistad M et al (2005).
Anxiolytic effects of intra-amygdaloid injection of the D1 antagonist SCH23390 in the rat. Neurosci Lett 377: 101-105.

Di Ciano P (2008). Drug seeking under a second-order schedule of reinforcement depends on dopamine D3 receptors in the basolateral amygdala. Behav Neurosci 122: 129-139.

DuBois DW, Perlegas A, Floyd DW, Weiner JL, McCool BA (2006). Distinct functional characteristics of the lateral/basolateral amygdala GABAergic system in C57BL/6J and DBA/2J mice. J Pharmacol Exp Ther 318: 629-640.

Faber ES, Callister RJ, Sah P (2001). Morphological and electrophysiological properties of principal neurons in the rat lateral amygdala in vitro. J Neurophysiol 85: 714-723.

Finckh U, Rommelspacher H, Kuhn S, Dufeu P, Otto G, Heinz A et al (1997). Influence of the dopamine D2 receptor (DRD2) genotype on neuroadaptive effects of alcohol and the clinical outcome of alcoholism. Pharmacogenetics 7: 271-281.

Fuxe K, Jacobsen KX, Hoistad M, Tinner B, Jansson A, Staines WA et al (2003). The dopamine D1 receptor-rich main and paracapsular intercalated nerve cell groups of the rat amygdala: relationship to the dopamine innervation. Neuroscience 119: 733-746.

Grabs D, Slepnev VI, Songyang Z, David C, Lynch M, Cantley LC et al (1997). The SH3 domain of amphiphysin binds the proline-rich domain of dynamin at a single site that defines a new SH3 binding consensus sequence. J Biol Chem 272: 13419-13425.

Gremel CM, Cunningham CL (2009). Involvement of amygdala dopamine and nucleus accumbens NMDA receptors in ethanol-seeking behavior in mice. Neuropsychopharmacology 34: 1443-1453.

Guitart-Masip M, Johansson B, Fernandez-Teruel A, Canete T, Tobena A, Terenius L et al (2006). Divergent anatomical pattern of D1 and D3 binding and dopamine- and cyclic AMP-regulated phosphoprotein of $32 \mathrm{kDa}$ mRNA expression in the Roman rat strains: implications for drug addiction. Neuroscience 142: 1231-1243.

Hammad H, Wagner JJ (2006). Dopamine-mediated disinhibition in the CA1 region of rat hippocampus via D3 receptor activation. J Pharmacol Exp Ther 316: 113-120.

Higley JD, Suomi SJ, Linnoila M (1991). CSF monoamine metabolite concentrations vary according to age, rearing, and sex, and are influenced by the stressor of social separation in rhesus monkeys. Psychopharmacology (Berl) 103: 551-556.

Inglis FM, Moghaddam B (1999). Dopaminergic innervation of the amygdala is highly responsive to stress. J Neurochem 72: 1088-1094.

Isoardi NA, Bertotto ME, Martijena ID, Molina VA, Carrer HF (2007). Lack of feedback inhibition on rat basolateral amygdala following stress or withdrawal from sedative-hypnotic drugs. Eur J Neurosci 26: 1036-1044.

Jones SR, Mickelson GE, Collins LB, Kawagoe KT, Wightman RM (1994). Interference by $\mathrm{pH}$ and $\mathrm{Ca}^{2+}$ ions during measurements of catecholamine release in slices of rat amygdala with fast-scan cyclic voltammetry. J Neurosci Methods 52: 1-10.

Kienast T, Hariri AR, Schlagenhauf F, Wrase J, Sterzer P, Buchholz HG et al (2008). Dopamine in amygdala gates limbic processing of aversive stimuli in humans. Nat Neurosci 11: 1381-1382.

Kittler JT, Delmas P, Jovanovic JN, Brown DA, Smart TG, Moss SJ (2000). Constitutive endocytosis of GABAA receptors by an association with the adaptin AP2 complex modulates inhibitory synaptic currents in hippocampal neurons. J Neurosci 20: 7972-7977.

Kroner S, Rosenkranz JA, Grace AA, Barrionuevo G (2005). Dopamine modulates excitability of basolateral amygdala neurons in vitro. J Neurophysiol 93: 1598-1610.

Lack AK, Diaz MR, Chappell A, DuBois DW, McCool BA (2007). Chronic ethanol and withdrawal differentially modulate pre- and 
postsynaptic function at glutamatergic synapses in rat basolateral amygdala. J Neurophysiol 98: 3185-3196.

Le Foll B, Goldberg SR, Sokoloff P (2005). The dopamine D3 receptor and drug dependence: effects on reward or beyond? Neuropharmacology 49: 525-541.

Marowsky A, Yanagawa Y, Obata K, Vogt KE (2005). A specialized subclass of interneurons mediates dopaminergic facilitation of amygdala function. Neuron 48: 1025-1037.

Matthews K, Dalley JW, Matthews C, Tsai TH, Robbins TW (2001). Periodic maternal separation of neonatal rats produces regionand gender-specific effects on biogenic amine content in postmortem adult brain. Synapse 40: 1-10.

McCool BA, Frye GD, Pulido MD, Botting SK (2003). Effects of chronic ethanol consumption on rat GABA(A) and strychninesensitive glycine receptors expressed by lateral/basolateral amygdala neurons. Brain Res 963: 165-177.

McDonald AJ, Betette RL (2001). Parvalbumin-containing neurons in the rat basolateral amygdala: morphology and co-localization of Calbindin-D(28k). Neuroscience 102: 413-425.

McDonald AJ, Mascagni F, Mania I, Rainnie DG (2005). Evidence for a perisomatic innervation of parvalbumin-containing interneurons by individual pyramidal cells in the basolateral amygdala. Brain Res 1035: 32-40.

Muller JF, Mascagni F, McDonald AJ (2007). Postsynaptic targets of somatostatin-containing interneurons in the rat basolateral amygdala. J Comp Neurol 500: 513-529.

Muller JF, Mascagni F, McDonald AJ (2009). Dopaminergic innervation of pyramidal cells in the rat basolateral amygdala. Brain Struct Funct 213: 275-288.

Nath C, Saxena RC, Gupta MB (2000). Effect of dopamine agonists and antagonists on the lorazepam withdrawal syndrome in rats. Clin Exp Pharmacol Physiol 27: 167-171.

Paxinos G, Watson C (1997). The Rat Brain in Stereotaxic Coordinates, 3rd edn. Academic Press: London, 80pp.

Pellow S, Chopin P, File SE, Briley M (1985). Validation of open:closed arm entries in an elevated plus-maze as a measure of anxiety in the rat. J Neurosci Methods 14: 149-167.

Phillips GD, Harmer CJ, Hitchcott PK (2002). Blockade of sensitisation-induced facilitation of appetitive conditioning by post-session intra-amygdala nafadotride. BehavBrain Res 134: 249-257.

Pinard CR, Muller JF, Mascagni F, McDonald AJ (2008). Dopaminergic innervation of interneurons in the rat basolateral amygdala. Neuroscience 157: 850-863.

Pitkanen A, Savander V, LeDoux JE (1997). Organization of intraamygdaloid circuitries in the rat: an emerging framework for understanding functions of the amygdala. Trends Neurosci 20: 517-523.

Ramanathan S, Tkatch T, Atherton JF, Wilson CJ, Bevan MD (2008). D2-like dopamine receptors modulate SKCa channel function in subthalamic nucleus neurons through inhibition of Cav2.2 channels. J Neurophysiol 99: 442-459.

Sanders SK, Shekhar A (1995). Regulation of anxiety by $\mathrm{GABA}_{\mathrm{A}}$ receptors in the rat amygdala. Pharmacol Biochem Behav 52: 701-706.

Schiess MC, Asprodini EK, Rainnie DG, Shinnick-Gallagher P (1993). The central nucleus of the rat amygdala: in vitro intracellular recordings. Brain Res 604: 283-297.

See RE, Kruzich PJ, Grimm JW (2001). Dopamine, but not glutamate, receptor blockade in the basolateral amygdala attenuates conditioned reward in a rat model of relapse to cocaine-seeking behavior. Psychopharmacology (Berl) 154: 301-310.

Silberman Y, Ariwodola OJ, Chappell AM, Yorgason JT, Weiner JL (2010). Lateral paracapsular GABAergic synapses in the basolateral amygdala contribute to the anxiolytic effects of beta 3 adrenoceptor activation. Neuropsychopharmacology 35: 1886-1896.

Silberman Y, Ariwodola OJ, Weiner JL (2009). Differential effects of $\mathrm{GABAB}$ autoreceptor activation on ethanol potentiation of local and lateral paracapsular GABAergic synapses in the rat basolateral amygdala. Neuropharmacology 56: 886-895.

Silberman Y, Shi L, Brunso-Bechtold JK, Weiner JL (2008). Distinct mechanisms of ethanol potentiation of local and paracapsular GABAergic synapses in the rat basolateral amygdala. J Pharmacol Exp Ther 324: 251-260.

Steiner H, Fuchs S, Accili D (1997). D3 dopamine receptordeficient mouse: evidence for reduced anxiety. Physiol Behav 63: 137-141.

Swant J, Stramiello M, Wagner JJ (2008). Postsynaptic dopamine D3 receptor modulation of evoked IPSCs via GABA(A) receptor endocytosis in rat hippocampus. Hippocampus 18: 492-502.

Szinyei C, Heinbockel T, Montagne J, Pape HC (2000). Putative cortical and thalamic inputs elicit convergent excitation in a population of GABAergic interneurons of the lateral amygdala. J Neurosci 20: 8909-8915.

Talalaenko AN, Abramets IA, Stakhovskii Yu V, Shekhovtsov AA, Chernikov AV, Shevchenko SL (1994). The role of dopaminergic mechanisms on the brain in various models of anxious states. Neurosci Behav Physiol 24: 284-288.

Vengeliene V, Leonardi-Essmann F, Perreau-Lenz S, GebickeHaerter P, Drescher K, Gross G et al (2006). The dopamine D3 receptor plays an essential role in alcohol-seeking and relapse. FASEB J 20: 2223-2233.

Washburn MS, Moises HC (1992). Electrophysiological and morphological properties of rat basolateral amygdaloid neurons in vitro. J Neurosci 12: 4066-4079.

Weiner JL, Gu C, Dunwiddie TV (1997). Differential ethanol sensitivity of subpopulations of GABAA synapses onto rat hippocampal CA1 pyramidal neurons. J Neurophysiol 77: 1306-1312.

Weiss F, Ciccocioppo R, Parsons LH, Katner S, Liu X, Zorrilla EP et al (2001). Compulsive drug-seeking behavior and relapse. Neuroadaptation, stress, and conditioning factors. Ann N Y Acad Sci 937: 1-26.

Woodruff AR, Monyer H, Sah P (2006). GABAergic excitation in the basolateral amygdala. J Neurosci 26: 11881-11887.

Wu PH, Poelchen W, Proctor WR (2005). Differential GABAB receptor modulation of ethanol effects on GABA(A) synaptic activity in hippocampal CA1 neurons. J Pharmacol Exp Ther 312: 1082-1089.

Xiang Z, Huguenard JR, Prince DA (2002). Synaptic inhibition of pyramidal cells evoked by different interneuronal subtypes in layer v of rat visual cortex. J Neurophysiol 88: 740-750.

Yang XM, Gorman AL, Dunn AJ, Goeders NE (1992). Anxiogenic effects of acute and chronic cocaine administration: neurochemical and behavioral studies. Pharmacol Biochem Behav 41: 643-650.

Yokoyama M, Suzuki E, Sato T, Maruta S, Watanabe S, Miyaoka H (2005). Amygdalic levels of dopamine and serotonin rise upon exposure to conditioned fear stress without elevation of glutamate. Neurosci Lett 379: 37-41. 